\title{
Initial Medication Adherence in the Elderly Using PACE Claim Reversals: A Pilot Study
}

\author{
Doris A. Forestal, MSc, PhD Candidate; Tamar A. Klaiman, PhD, MPH; \\ Andrew M. Peterson, PharmD, PhD; and Debra A. Heller, PhD, MPH
}

\begin{abstract}
BACKGROUND: The Medicare Modernization Act, with its requirements for Medicare Part $D$ to comply with electronic prescribing (e-prescribing), bolstered the adoption of e-prescribing, which increased to $73 \%$ in 2013 . Therefore, understanding whether electronic prescriptions are less likely to be picked up is important as e-prescribing continues to be emphasized.

OBJECTIVE: To assess whether prescription origin is among the factors associated with initial medication adherence, using claim reversals as a proxy measure.

METHODS: A cross-sectional study was completed using a sample of reversed claims from the Pharmaceutical Assistance Contract for the Elderly (PACE) program for September 2014. The total number of reversed claims for new prescriptions $(15,966)$ was categorized by prescription origin (written, telephone, electronic, fax, and pharmacy). Using a chi-square analysis, the reversed claims were compared among prescription origin to determine if there is a difference in the proportion of electronic prescriptions reversed compared with those from other origins.

RESULTS: When compared with all other prescription origins, electronic prescriptions $(E)$ were more likely to be reversed at day $0(E=50 \%$, any other $[A 0]=49 \%, P<0.05)$ and after day $0(E=58 \%, A 0=42 \%, P<0.05)$.

CONCLUSIONS: Electronic prescriptions are associated with a higher rate of claim reversals and may reflect poorer initial adherence. Electronic prescriptions may more likely be forgotten or not picked up because they were not presented to the pharmacy by the patient. The growing adoption of electronic prescriptions merits particular attention, since it may be a factor in initial medication adherence in the elderly.
\end{abstract}

J Manag Care Spec Pharm. 2016;22(9):1046-50

Copyright $\odot 2016$, Academy of Managed Care Pharmacy. All rights reserved.

\section{What is already known about this subject}

Electronic prescribing may promote medication adherence. Electronic prescriptions are about $65 \%$ less likely to be picked up.

\section{What this study adds}

Electronic prescribing is associated with a higher rate of claim reversals and may reflect poorer initial adherence.

Adoption of electronic prescriptions may be a factor in poor initial medication adherence.

Evidence is provided that would warrant a larger study regarding the relationship between initial medication adherence and electronic prescribing.
$\mathrm{P}$ oor medication adherence represents a substantial problem in the United States, with an estimated 125,000 deaths occurring annually because patients do not take their medications as prescribed. ${ }^{1-3}$ Resulting health care costs are estimated to be over $\$ 100$ billion. ${ }^{4}$ Electronic prescribing (e-prescribing) has been promoted as a means to increase medication adherence, but some patients may be less likely to pick up these types of prescriptions..$^{5}$ Thus, e-prescribing merits attention, since it may affect claim reversals and initial medication adherence, which is causing increasing concerns for policymakers, health care providers, and payers.

E-prescribing increases efficiency by automating the communication of prescriptions to pharmacies, which reduces costs for payers. ${ }^{6}$ In addition, electronic prescriptions (e-prescriptions) are expected to reduce medication errors by enhancing legibility and decreasing the risk of adverse events in patients by flagging potential drug interactions. ${ }^{6}$ Further, e-prescribing provides a good return on investment for payers through greater physician compliance with formularies and more generic prescribing. ${ }^{6,7}$ E-prescribing increased to $73 \%$ in 20138; therefore, understanding whether e-prescriptions are less likely to be picked up is important, since e-prescribing continues to be emphasized.

\section{Defining Medication Adherence}

Medication adherence, often referred to as patient compliance, is generally defined as "the extent to which patients take medications as prescribed by their healthcare providers." ${ }^{\prime 9}$ There are 2 types of medication adherence: initial medication adherence, which refers to the filling of a prescription for the first time, and continued adherence, which refers to the refilling of prescriptions. ${ }^{9,10}$ Initial medication adherence involves 2 steps for the patient: presenting the prescription and retrieving the medication. This study focused on the second step, that is, whether the patient retrieved the medication from the pharmacy.

\section{Difficulty in Assessing Initial Medication Adherence}

Initial medication adherence rates have been difficult to assess because of challenges in obtaining information regarding patients' actions once they receive a prescription from their physicians and in tracking physician prescription orders. ${ }^{10,11}$ Most published studies that have focused on adherence have been based on prescription refills using pharmacy claim databases, which include only records of dispensed prescriptions; 
consequently, studies on initial medication adherence are scarce. ${ }^{10,12}$ The emergence of e-prescribing provides an opportunity to track prescribers' orders and whether patients filled their first prescriptions (initial medication adherence).

Despite the important findings that have resulted from the few studies linking e-prescribing data with dispensed prescriptions, a general lack of systematic data on new prescriptions that remain unfilled continues to be a major limitation for research on initial adherence. One resource that may be useful for identifying cases of initial nonadherence is pharmacy claim databases, which include reversed claims data. An interesting consideration is the potential difference in claim reversals across different prescription origins, with the general expectation that prescription origin should be associated with reversal rates, if reversals of new prescriptions are a result of primary nonadherence. For example, e-prescriptions are transmitted to pharmacies independently of patients and are typically billed before the patients arrive to pick up the prescriptions. Later, the prescriptions are reversed if they are never picked up. Claim reversal rates may therefore be indicative of dispensing rates and whether patients picked up their prescriptions. So, any observed differences in reversal rates across prescription origin may provide useful information about the degree to which reversals reflect patient failure to retrieve medication, as part of the initial medication adherence phase.

The purpose of this pilot study was to assess if prescription origin is among the factors associated with initial medication adherence among noninstitutionalized elderly in Pennsylvania.

\section{Methods}

Using claim reversals as a proxy measure, we assessed whether prescription origin is associated with initial medication adherence. Prescription claim data were provided by Pennsylvania's Pharmaceutical Assistance Contract for the Elderly (PACE), a state-funded program that provides prescription assistance to income-eligible elderly. During 2014, PACE subsidized the cost of prescription drugs for over 300,000 elderly beneficiaries. ${ }^{13}$ Cardholders were responsible for a flat copayment on each prescription. This cross-sectional study was completed using a sample of reversed claims from the PACE database for September 2014. Reversed claims are prescriptions that were initially billed to PACE but then later reversed by the pharmacy. Claims are submitted when prescriptions are presented but before the medications are dispensed. If a claim has been submitted and paid for, but the prescription has not been dispensed to the cardholder, then providers submit a reversal no later than 30 days beyond the date of dispensing/submission. ${ }^{14}$

For the purposes of this study, only reversed claims for new prescriptions were included to ensure that the analysis was focused on initial medication adherence and not continued adherence. Reversed claims for new prescriptions were defined as claims that had a refill number of 0 submitted by the phar- macy (indicating a new prescription) and the PACE cardholder in question had no previous claims for this Generic Code Number (GCN) in PACE's claims history during the preceding 180 days. GCN is a proprietary coding system used by First DataBank to uniquely define drugs on the basis of strength, form code, and route of administration. ${ }^{15}$ The hypothesis for this study was that there is a difference in the proportion of reversed claims for e-prescriptions compared with all other prescriptions.

The most recent data available for use in this study were from September 2014. PACE claim reversals varied from 9.8\% to $11.2 \%$ in 2014 with an average of $10.5 \%$ for the year. In September 2014, PACE received claims for 148,325 new prescriptions, of which 15,966 claims were reversed (10.8\% of total prescriptions). These data were de-identified for analysis purposes and categorized by prescription origin (written [W]: 23\%, telephone [T]: 12\%, electronic [E]: 49\%, fax [F]: 15\%, and pharmacy $[\mathrm{P}]:<1 \%)$. Using a chi-square analysis goodness of fit test, the groups of reversed claims per prescription origin were compared to assess whether there was a difference in the proportions of reversed claims across prescription origins. Then, the group of reversed claims for e-prescriptions was compared with all other prescription origins to test if there was a difference in the proportion of e-prescriptions not picked up versus those from other origins. To calculate the expected proportions of reversed prescriptions, we assumed that each prescription had an equal likelihood of reversal, regardless of the origin. This meant that if $50 \%$ of the prescriptions were received electronically, we expected to see $50 \%$ of the reversals originate electronically. The unit of analysis was a group of reversed claims, and alpha was set at 0.05 for a two-tailed test.

This study was certified as nonhuman research by the Institutional Review Board for the Protection of Human Subjects at the University of the Sciences in Philadelphia.

\section{Results}

PACE received claims for payment for 148,325 prescriptions in September 2014. Of these claims, 15,966 claims were later reversed by the pharmacies. Claim reversals for September 2014 occurred from day 0 (the day prescriptions were received) to day 52 after the original submission of the prescriptions to the pharmacies.

A comparison of the distribution of claim reversals at day 0 across prescription origins showed statistical significance, suggesting a difference in the proportions of claims reversed on the first day $(\mathrm{W}=25 \%, \mathrm{~T}=12 \%, \mathrm{E}=50 \%, \mathrm{~F}=10 \%$, and $\mathrm{P}=2 \%$; $P<0.001)$. The same observation was made when comparing the proportions of reversed claims after day $0(\mathrm{~W}=9.5 \%$, $\mathrm{T}=9 \%, \mathrm{E}=58 \%, \mathrm{~F}=22 \%$, and $\mathrm{P}=1.3 \% ; \mathrm{P}<0.001$ ). These results showed a difference in the proportion of claim reversals across prescription origins, indicating an association between claim reversal and prescription origin. This difference was further investigated, taking into consideration the hypothesis that 

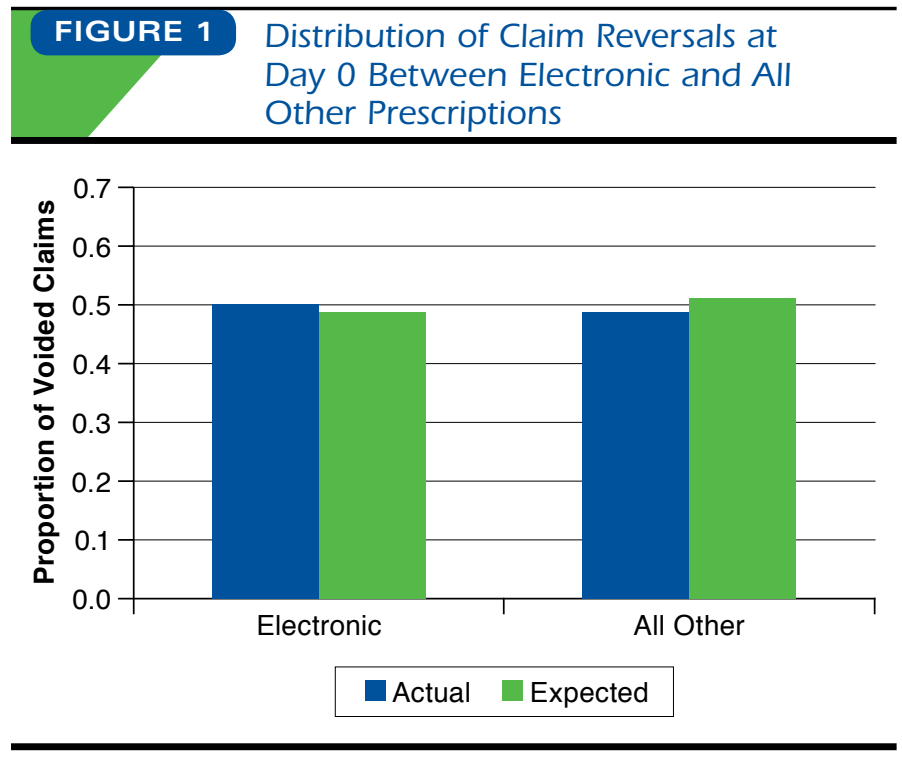

e-prescriptions are more likely to be reversed than all other prescriptions. A comparison of e-prescriptions with all other prescription origins pooled together at day 0 showed statistical difference, despite the proportions being very similar ( $\mathrm{E}=50 \%$, any other $[\mathrm{AO}]=49 \%, P=0.006$; Figure 1 ). This small difference is not clinically significant, suggesting that all prescriptions have a nearly equal chance of being voided on the day of submission.

A statistically significant difference was also seen for the same comparison after day $0(\mathrm{E}=58 \%, \mathrm{AO}=42 \%, \mathrm{P}<0.001$; Figure 2). E-prescriptions appear to be associated with a higher rate of claim reversals compared with all other prescription origins. One distinctive factor for e-prescriptions that may explain this difference is that e-prescriptions bypass the patient and are transferred directly to the pharmacy.

\section{Discussion}

This study showed differences in the distribution of claim reversals at day 0 and after day 0 across prescription origins, which suggests an association between reversed claims and prescription origin. When compared with all other prescription origins, e-prescriptions were more likely to be reversed, confirming our hypothesis that there is a difference in the proportion of reversed claims for e-prescriptions compared with all other prescriptions. Consistent with these findings, Shrank et al. (2010) found that e-prescriptions were almost $65 \%$ more likely to be abandoned than those delivered to the pharmacy by other means. ${ }^{16}$ Moreover, Fisher et al. (2011) reported 24\% of new e-prescriptions were not filled within 6 months. ${ }^{17}$ Prescriptions sent electronically may be more likely to be forgotten or not picked up because they were not presented to the pharmacy by the patient.
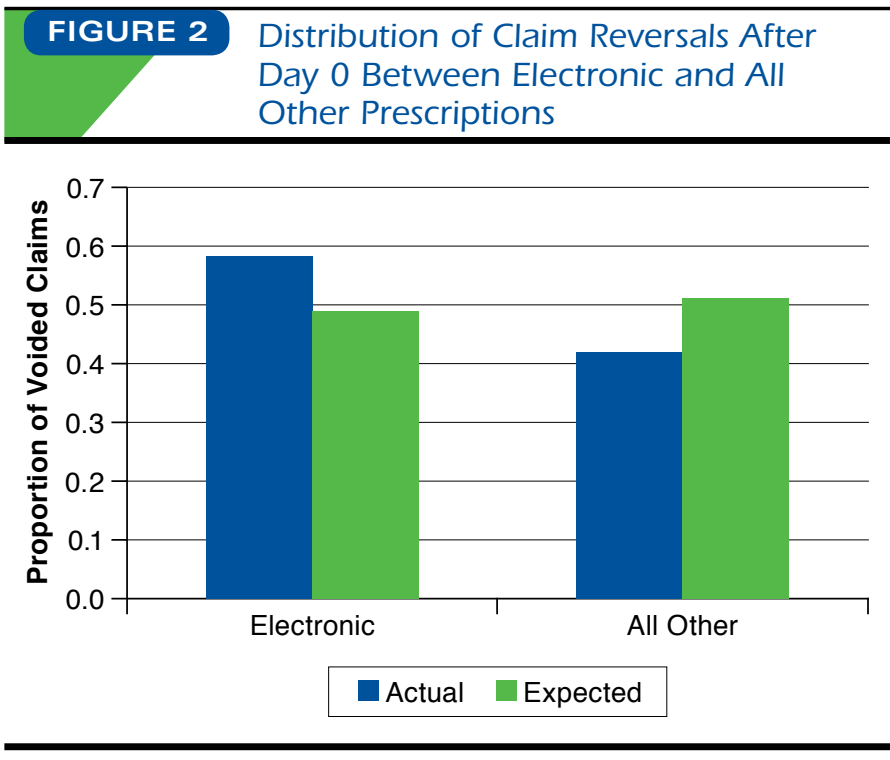

Claim reversals for e-prescriptions require particular attention, since e-prescribing may have countervailing effects on initial medication adherence. Interventions targeting e-prescriptions may be needed to motivate patients to retrieve their medications, perhaps by focusing on pharmacy policies for follow-up with patients. Pharmacy best practices may inform interventions to decrease claim reversals, thus, promoting initial medication adherence. ${ }^{18}$

\section{Limitations}

This study focused on PACE claim reversals data, which reflected initial medication adherence only for PACE beneficiaries in Pennsylvania. One potential limitation of this study is that, because of its income requirements, the PACE population is not representative of the entire U.S. elderly population. On average, PACE participants have lower incomes, are older, and are more likely to be widowed and female, compared with the general U.S. elderly population aged 65 years and older. The PACE population can be described as near-poor but with incomes higher than those found in the Medicaid population. During 2014, the median income of single PACE cardholders was $\$ 15,989$ (136\% of the federal poverty level [FPL]), and the median income of married PACE cardholders was $\$ 26,270$ (165\% of FPL).$^{14}$ The PACE upper income limits are currently $\$ 23,500$ for single cardholders and $\$ 31,500$ for married cardholders, which corresponds to $200 \%$ and $198 \%$ of FPL, respectively. Therefore, this study's findings may not be generalizable to the elderly across all income ranges. However, given that $33 \%$ of U.S. elderly in 2014 had incomes placing them below $200 \%$ of FPL, ${ }^{19}$ it may be argued that the PACE population is representative of an important segment of all U.S. elderly. Our 
findings may therefore be relevant to many programs providing prescription drug benefits to the elderly, including Medicare Part D programs. ${ }^{20}$ Similar studies using health systems from other states would be needed to increase generalizability of these data.

Another limitation is that only analyzed claim reversals data for September 2014 were examined; a sample that includes a longer period of time would provide more accurate information on the pattern of claim reversals across prescription origins. Also, the PACE dataset did not include prescribers' orders, which would be needed to fully assess whether patients actually retrieved prescriptions received from their physicians. Thus, claims data are not ideal to study initial medication adherence. ${ }^{21,22}$

Higher reversal rates do not necessarily correlate with higher nonadherence rates, since several factors may affect claim reversals (e.g., generic substitution, patient's use of another insurance card, or use of samples). ${ }^{17}$ However, the patterns of differences observed in this study for electronic versus nonelectronic prescription origins, and for day 0 versus later claim reversals, are consistent with claim reversals occurring as a result of prescriptions never picked up. Further research is needed to evaluate the validity of using electronic claim reversal data to identify initial medication nonadherence. We believe that our results will help generate hypotheses on which to focus a larger study aimed at addressing these questions.

\section{Conclusions}

Studies on initial medication adherence are scarce, despite it being an important step in the pharmaceutical treatment of health conditions. E-prescriptions were promoted to reduce medication errors and cost and increase efficiency and are required for health plans participating in Medicare Part D. Claim reversals for e-prescriptions merit particular attention, since e-prescribing may have countervailing effects on initial medication adherence. ${ }^{5}$ This pilot study provides evidence that would warrant a larger study of the relationship between initial medication adherence and e-prescriptions.

\section{Authors}

DORIS A. FORESTAL, MSc, PhD Candidate; TAMAR A. KLAIMAN, PhD, MPH; and ANDREW M. PETERSON, PharmD, $P h D$, University of the Sciences in Philadelphia, Philadelphia, Pennsylvania. DEBRA A. HELLER, PhD, MPH, Magellan Medicaid Administration/PACE, Harrisburg, Pennsylvania.

AUTHOR CORRESPONDENCE: Doris A. Forestal, MSc, PhD Candidate, University of the Sciences in Philadelphia, 600 S. 43rd St., Box 22, Philadelphia, PA 19104. E-mail:dforestal@mail.usciences.edu.

\section{DISCLOSURES}

This study was not supported by any funding. Peterson reports advisory board and consultancy fees from IMS Health and Pfizer and employment by Genentech. Klaiman is currently employed by AccessMatters. No other financial or other conflicts of interests were reported.

Study concept and design were primarily contributed by Forestal, along with Klaiman and Peterson. Heller took the lead in data collection, along with Forestal, and data interpretation was performed by Forestal, Klaiman, and Peterson. Forestal, Klaiman, and Heller were responsible for manuscript preparation.

\section{REFERENCES}

1. Bosworth HB, Granger BB, Mendys P, et al. Medication adherence: a call for action. Am Heart J. 2011;162(3):412-24.

2. Horwitz RI, Viscoli CM, Donaldson R, et al. Treatment adherence and risk of death after a myocardial infarction. Lancet. 1990;336(8714):542-45.

3. McCarthy R. The price you pay for the drug not taken. Bus Health. 1998; 16(10):27-28, 30, 32-33.

4. The Boston Consulting Group. The hidden epidemic: finding a cure for unfilled precriptions and missed doses. December 2003. Available at: https://www.bcg.com/documents/file14265.pdf. Accessed July 11, 2016.

5. Lapane KL, Dubé C, Schneider KL, Quilliam BJ. Patient perceptions regarding electronic prescriptions: is the geriatric patient ready? J Am Geriatr Soc. 2007;55(8):1254-59.

6. Friedman MA, Schueth A, Bell DS. Interoperable electronic prescribing in the United States: a progress report. Health Aff (Millwood). 2009;28(2):393-403

7. Elson B. Electronic prescribing in ambulatory care: a market primer and implications for managed care pharmacy. J Manag Care Pharm. 2001:7(2):115-20. Available at: http://www.jmcp.org/doi/abs/10.18553/ jmcp.2001.7.2.115.

8. Surescripts. 2013 national progress report and safe-Rx ranking. 2013. Available at: http://surescripts.com/docs/default-source/national-progressreports/surescripts_2013_national_progress_report.pdf?sfvrsn=2. Accessed July 11, 2016.

9. Cramer JA, Roy A, Burrell A, et al. Medication compliance and persistence: terminology and definitions. Value Health. 2008;11(1):44-47.

10. Zeber JE, Manias E, Williams AF, et al. A systematic literature review of psychosocial and behavioral factors associated with initial medication adherence: a report of the ISPOR Medication Adherence \& Persistence Special Interest Group. Value Health. 2013;16(5):891-900.

11. Shah NR, Hirsch AG, Zacker C, Taylor S, Wood GC, Stewart WF. Factors associated with first-fill adherence rates for diabetic medications: a cohort study. J Gen Intern Med. 2009;24(2):233-37.

12. Fischer MA, Stedman MR, Lii J, et al. Primary medication nonadherence: analysis of 195,930 electronic prescriptions. J Gen Intern Med. 2010;25(4):284-90

13. National Conference of State Legislatures. State pharmaceutical assistance programs. Updated December 30, 2015. Available at: http://www. ncsl.org/research/health/state-pharmaceutical-assistance-programs.aspx. Accessed July 11, 2016

14. Pennsylvania Department of Aging. Pharmaceutical Assistance Contract for the Elderly annual report to the Pennsylvania General Assembly, January 1-December 31, 2014. Available at: http://www.aging.pa.gov/publications/ annual-reports/Documents/2014\%20PACE\%20Annual\%20Report.pdf. Accessed July 11, 2016

15. Abramson RG, Harrington CA, Missmar R, Li SP, Mendelson DN. Generic drug cost containment in Medicaid: lessons from five state MAC programs. Health Care Financ Rev. 2004;25(3):25-34.

16. Shrank WH, Choudhry NK, Fischer MA, et al. The epidemiology of prescriptions abandoned at the pharmacy. Ann Intern Med. 2010;153(10):633-40. 
17. Fischer MA, Choudhry NK, Brill G, et al. Trouble getting started: predictors of primary medication nonadherence. Am J Med. 2011;124(11):1081. e9-22.

18. Sommers SD, Kent DJ, Beam B, Boles M, Antoniskis D. A team approach to address antiretroviral therapy adherence barriers in a managed care organization. J Manag Care Pharm. 2001:7(3):214-18. Available at: http://www. jmcp.org/doi/abs/10.18553/jmcp.2001.7.3.214.

19. DeNavas-Walt C, Proctor BD, U.S Census Bureau. Income and poverty in the United States: 2014. Current Population Reports, P60-252. U.S. Government Printing Office. Washington, DC. 2015. Available at: https:// www.census.gov/content/dam/Census/library/publications/2015/demo/p60252.pdf. Accessed July 11, 2016.
20. Centers for Medicare \& Medicaid Services, U.S. Department of Health and Human Services. Medicare program; e-prescribing and the prescription drug program. Final rule. Fed Regist. 2005;70(214):67567-95.

21. Richards KM, Shepherd MD. Claims data and drawing appropriate conclusions. J Manag Care Pharm. 2002;8(2):152. Available at: http://www.jmcp. org/doi/abs/10.18553/jmcp.2002.8.2.152.

22. Fairman K, Motheral B. Evaluating medication adherence: which measure is right for your program? J Manag Care Pharm. 2000;6(6):499-504. Available at: http://www.jmcp.org/doi/abs/10.18553/jmcp.2000.6.6.499. 